\title{
Sputtered Hf-Ti nanostructures: A segregation and high-temperature stability study
}

Mikhail N. Polyakov, ${ }^{\mathrm{a}}$ Tongjai Chookajorn, ${ }^{\mathrm{b}, \mathrm{c}}$ Matthew Mecklenburg, ${ }^{\mathrm{d}}$ Christopher A. Schuh, ${ }^{\mathrm{b}}$ Andrea M. Hodge $\mathrm{a}^{\mathrm{a}, \mathrm{e},}$

${ }^{a}$ Department of Aerospace and Mechanical Engineering, University of Southern California, Los Angeles, CA 90089, USA

${ }^{\mathrm{b}}$ Department of Materials Science and Engineering, MIT, 77 Massachusetts Avenue, Cambridge, MA 02139, USA

'National Metal and Materials Technology Center (MTEC), National Science and Technology Development Agency (NSTDA), Pathum Thani 12120, Thailand

${ }^{\mathrm{d}}$ Center for Electron Microscopy and Microanalysis, University of Southern California, Los Angeles, CA 90089, USA

${ }^{\mathrm{e}}$ Department of Chemical Engineering and Materials Science, University of Southern California, 3650 McClintock Ave., Los Angeles, CA 90089, USA

*Corresponding author. Tel.: +1 (213) 740 4225; fax: +1 (213) 740 8071; e-mail: ahodge@usc.edu

mnpolyakov@gmail.com

tongjai.cho@mtec.or.th

$\underline{\text { m.h.mecklenburg@gmail.com }}$

schuh@mit.edu

\section{Abstract}

High-temperature stability and segregation tendency of a Hf-Ti alloy is investigated using specimens sputtered in monolithic and multilayerconfigurations. Upon annealing at $800{ }^{\circ} \mathrm{C}$ for 96 hours, the alloy shows segregation ofHf and Ti at the nanoscale even though the bulk Hf-Ti phase diagram predicts a homogeneous solid solution. The length scale of segregation is found to depend upon the initial as-depositedstructure, with the monolithic film showing Ti segregation at 
grain boundaries, and the multilayered specimens showing a nanostructureof Hf-rich grains and Ti-rich intergranular amorphous regions. The multilayer specimens exhibit similar post-annealing grain diameters even when the initiallayerthickness is varied. Thermodynamic Monte Carlo simulations show a solid solution when the bulk constraint is imposed,in line with the phase diagram expectation, and a polycrystalline nanostructurewith solute segregated intergranular regions with full equilibration, in general agreement withthe experimental observations.

Keywords: Multilayers, sputter deposition, nanostructured metals, thermodynamic stability, Monte Carlo simulation 


\section{Introduction}

Nanostructured materials havemany attractive properties,butthey generally exhibit poor thermal stabilitydue to theirmyriadinterfaces, which can both act as channels for diffusion and drive grain growth by providing excess free energy [1-4]. Some nanostructured materials, such as Al andPd, can show appreciable grain growth even at room temperature[5,6]. This grain growth severely limits the materials'application relevance, since theirproperties often degrade with increasing grain size.

Several techniques have been introducedto limit grain growth in nanostructured materials. Methods which focus on the kinetics of the system include the addition of solutes or secondphase particles which pin the grain boundaries or retard their movement[7-12]. On the other hand, techniques which focus on thermodynamicsdo not simply slow the grain boundary migration, but relieve the grain boundary excess energy by the addition of solutes[13-15]. One modelbuilt on this approach examined the energetics of different grain sizes and compositions, andclassified many binary systems by their proclivity fornanograin stability[16, 17]. In line with predictions, the W-Ti system was experimentally demonstrated to have stabilizednanograins at elevated temperatures $\left(1100^{\circ} \mathrm{C}\right)[18]$. However, in that study the nanograined material was produced by a ball-milling technique, whichcan result in chemical contamination, as well as a microstructure that is rich in dislocations and other defects, all of which affect the energetics of the system[19, 20].

To minimize the influence of such processing-related artifacts, the present study uses magnetron sputtering to synthesize nanostructured Hf-Ti materials, with the goal of testing their thermal stabilityfor different initial grain sizes. While the thermal stabilities of ternary systems containing Hf and Ti have been investigated for shape memory alloys and metallic glasses, an investigation into the nanograin stability of the binary Hf-Ti system at high temperatures is lacking [21-23].The aforementionedthermodynamic stability modelhas suggestedthat the Hf-Ti systemcould beeither stable or metastable in a nanograin configuration[17], interestingly, in a temperature range where the two elements are fully miscible[24]. In order to control the initial nanostructure, the Hf-Ti samples were sputtered as nanometallic multilayers, with alternating nanometer thick layers of pure Ti and co-sputtered Hf-Ti. The use of this multilayered geometry allows for control of the grain size (which correlates to the layer thickness) and provides the ability to distribute the $\mathrm{Ti}$ in nanoscale proximity to the Hf-rich regions, which should lower the kinetic barrier between the initial and expected equilibrium microstructures.

\section{Methods}

\subsection{Experimental}


Samples were synthesized using DC magnetron sputtering, with two sputtering sources being used to deposit Hf and Ti onto (100) Si substrates. The sampledescriptions are shown in Table 1, where Samples A and B consist of alternating pure Ti and co-sputtered Hf-Ti layers. The following sputtering conditions were used: 60 Watts for Ti, 200 Watts for $\mathrm{Hf}$, and a $0.67 \mathrm{~Pa}$ Argon pressure, with the on-times for the Hf source being varied to produce samples with differing layer thicknesses.

Table 1: Multilayered Hf-Ti sample descriptions.

\begin{tabular}{|c|c|c|c|c|}
\hline Sample name & $\begin{array}{c}\text { Hf-Ti layer } \\
\text { thickness }(\mathrm{nm})\end{array}$ & $\begin{array}{c}\text { Ti layer thickness } \\
(\mathrm{nm})\end{array}$ & $\begin{array}{c}\text { Overall sample } \\
\text { thickness }(\mu \mathrm{m})\end{array}$ & $\begin{array}{c}\text { Composition } \\
(\text { at.\% Ti) }\end{array}$ \\
\hline Sample A & 15 & 2 & 1.6 & 23 \\
\hline Sample B & 40 & 5 & 2.1 & 24 \\
\hline
\end{tabular}

An XP-2 profilometer (AMBiOS)was used to measure as-sputtered sample thicknesses, after which the samples wereremoved from the Si substrates. The samples were then subjected to an $800{ }^{\circ} \mathrm{C}$ heat treatment for 96 hours under vacuum (pressure $\approx 4 \times 10^{-4} \mathrm{~Pa}$ ) in a GSL1100X tube furnace (MTI Corporation). The heat treated samples will be referred to as HT-Sample A and HT-Sample B. At the end of the heat treatment, quenching was performed in low vapor pressure oil (Invoil 705, Inland Vacuum Industries) without breaking the vacuum. The samples were then removed from the oil and cleaned with ethanol. Samples for transmission electron microscopy (TEM) were prepared by Focused Ion Beam (FIB) liftout using a JIB-4500 FIB (JEOL). TEM, scanning TEM (STEM), andEnergy Dispersive X-ray spectroscopy (EDX) were performed in a JEM-2100Ftransmission electron microscope (JEOL). A JSM-7001 scanning electron microscope (SEM) was used to determine global compositions by EDX (JEOL).

\subsection{Modeling}

A lattice Monte Carlo method was used to simulate the equilibrium structure of a binary alloy at finite composition and temperature by considering both chemical and topological arrangements. Each lattice site maintains two state variables: the chemical type, which can be assigned as a solvent or solute atom, and the grain number, which denotes the group of atoms that belong to the same grain. The model accounts for mixing interactions within granular and intergranular regions using two different interaction energies, $\omega_{\mathrm{c}}$ and $\omega_{\mathrm{gb}}$, respectively, and the details on bond energy calculations can be found in Ref. [25]. The structure evolves by changes in the chemical distribution and grain structure. A chemical switch selects two lattice sites at random and exchanges their atom types. A grain switch allows a lattice site next to a grain boundary to change its grain allegiance. For the hexagonal close packed lattice used in the present study, if such a lattice site is surrounded by 11 or 12 neighbors of the same grain number, the majority 
grain number is attempted. Otherwise, the grain number of one of its neighbors across a grain boundary or a unique grain number (which represents nucleation of a new grain) is attempted. A switch that evolves the system to a lower energy state is always executed, while a switch that evolves the system to a higher internal energy $E_{2}$ relative to the initial internal energy $E_{1}$ is

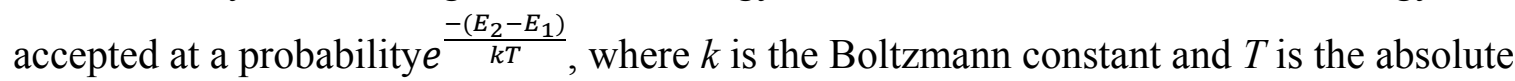
temperature.

The structure is initialized ina randomized state, with regard to both chemical and grain number distributions, at $10,000 \mathrm{~K}$ and slowly cooled at a rate $\frac{-\left(T_{\text {step }}-T_{\text {final }}\right)}{5000}$, where the denominator is in units of Monte Carlo steps, until the final temperature $T_{\text {final }}=1073 \mathrm{~K}$ is reached. During each Monte Carlo step, one switch per atom is attempted on average across the whole system at the intermediate temperature $T_{\text {step. }}$. A total of 100,000 Monte Carlo steps are performed, which is foundto achieve anequilibrated state (i.e., slower cooling produces the same essential state) for the present conditions. Periodic boundary conditions were imposed on the three principal axes, and all simulations employ a hexagonal close packed lattice with 560x 560x 6 sites, which is equivalent to $180 \mathrm{~nm}$ in width and encompasses a total of 1,881,600atoms. All simulated structures that follow are presented in a cross-sectional view onto a (001) plane.

For simulation of the Hf-Ti system studied here, we use the bond energies $E_{\mathrm{c}}^{\mathrm{HfHf}}=1.61 \mathrm{eV}, E_{\mathrm{c}}^{\mathrm{TiTi}}$ $=1.25 \mathrm{eV}, E_{\mathrm{c}}^{\mathrm{HfTi}}=1.42 \mathrm{eV}, E_{\mathrm{gb}}^{\mathrm{HfHf}}=1.58 \mathrm{eV}, E_{\mathrm{gb}}^{\mathrm{TiTi}}=1.22 \mathrm{eV}$, and $E_{\mathrm{gb}}^{\mathrm{HfTi}}=1.44 \mathrm{eV}$, where the subscript indicates a bond in a crystal (c) or grain boundary (gb) region, and the superscript denotes the chemical pair. Other relevant material parameters are the atomic volume $\Omega_{\mathrm{Hf}}=13.44$ $\mathrm{cm}^{3} / \mathrm{mol}, \Omega_{\mathrm{Ti}}=10.64 \mathrm{~cm}^{3} / \mathrm{mol}$, hexagonal close-packed (HCP) coordination number of 12 , and grain boundary thickness of $0.5 \mathrm{~nm}$. These bond energies yield reasonable values for the pure componentgrain boundary energies $\gamma_{0, \mathrm{Hf}}=0.72 \mathrm{~J} / \mathrm{m}^{2}, \gamma_{0, \mathrm{Ti}}=0.68 \mathrm{~J} / \mathrm{m}^{2}$, as well as the bulk interaction energy $\omega_{\mathrm{c}}$ of $13 \mathrm{meV}$ and the grain boundary interaction energy $\omega_{\mathrm{gb}}$ of $-39 \mathrm{meV}$.

\section{Results and Discussion}

\subsection{Microstructure and Grain Evolution}

The microstructures of the as-sputtered samples are shown in the cross-sectional TEM images in Fig.1. Fig.1a and 1c are bright-field TEM (BF-TEM) images of Sample A and B, respectively. The bright layers are $\mathrm{Ti}$, the dark layers are $\mathrm{Hf}-\mathrm{Ti}$, and the growth direction is vertical, as indicated by the arrow. EDX scans by SEMshowed overall compositions of approximately 23 at.\% Ti for Sample A and 24 at.\% Ti for Sample B. Fig. 1b and 1dare dark-field TEM (DFTEM) images ofSample A and B, respectively. There is a columnar structure in the as-sputtered samples, andstrong $\mathrm{Hf}(002)$ diffraction spots, as indicated by the inset selected area electron 
diffraction (SAED) patterns. The average widths of the columnar grainsarelarger for Sample $\mathrm{B}(40 \mathrm{~nm})$ than for Sample A $(25 \mathrm{~nm})$, and their size distributions will be discussed later.

In order to investigate the thermal stability of both structures, the samples were heat-treated as explained inSection 2.1, and cross-sectional TEM images of the heat-treated samples are shown in Fig. 2 in three different TEM imaging modes, with HT-Sample A on the left and HT-Sample $\mathrm{B}$ on the right. The BF-TEM images, Fig. 2a and 2d, show the nanocrystallinity of the samples, as well as loss of the layered structure (the growth direction is indicated by the arrow on the left).The inset diffraction patterns have superimposed diffraction rings of $\mathrm{Hf}$ (bottom right) and $\mathrm{HfO}_{2}$ (top right) andindicate that, though the samples were heat treated in vacuum, there is a mixture of $\mathrm{Hf}$ and $\mathrm{HfO}_{2}$. The DF-TEM images, Fig. $2 \mathrm{~b}$ and $2 \mathrm{e}$, show that the grains are relatively equiaxed and that the initial columnar structurehas been lost. Finally, the annular dark-field (ADF) STEM images, Fig.2c and 2f, show a strong segregation into Ti-rich regions (dark), and Hf-rich regions (bright), which was confirmed by EDX mapping (shown later in the manuscript). Note that the structures of HT-Sample A and HT-Sample B are similar in all of the images.

Since the columnar structure as well as the chemical layering was lost after the heat treatments, an additional sample was co-sputtered (referred to as Sample C) in order to investigatewhether the Ti interlayers were responsible for the formation of equiaxed grains. Sample $\mathrm{C}$ is a monolithic Hf-Ti film, with a slightly lower Ti concentration (20 at.\% Ti) than the multilayered samples. Sample C initially had columnar grains (Fig.3a, DF-TEM cross-sectional image), but, after a 96 hour, $800{ }^{\circ} \mathrm{C}$ heat treatment and quenching, the columnar structure was lost, and equiaxed grains resulted. This is shown in Fig. $3 \mathrm{~b}$ and $3 \mathrm{~d}$, which are cross-sectional ADF-STEM and DF-TEM images, respectively. In Fig. 3b, Hf-rich regions are dark and Ti-rich regions are bright; this reversal in contrast compared to Fig. $2 \mathrm{c}$ and $2 \mathrm{f}$ is due to the differences in thicknesses of the FIB-prepared samples. Based on this heat-treated monolithic sample, HT-Sample C, the thin Ti interlayers do not appear to be responsible for the loss of the columnar grains in the multilayered samples with annealing, and it would appear that this system has an intrinsic preference to evolve to an equiaxed grain structure with Ti situated around Hf-rich grains, independently of the initial structure. Thisevolution of the structure to the equiaxed configuration will be studied in future work; this manuscript will instead focus on the equiaxed structure itself, and its energetics.

DF-TEM images were used to measure the grain sizes of the samples before and after heat treatment. By assuming a cylindrical grain geometry, the average columnwidthsof the assputtered samples were measured at several points on each columnar grain, as indicated by the yellow double-sided arrows on Fig.1d(color online). For the heat-treated samples, the areas of individual grains were determined from DF-TEM images, such as in Fig. $2 b$ and $2 \mathrm{e}$, and equivalent diameters were calculated assuming spherical grains. The size distributions for the 
samples are given in Fig.4. For Sample A, the average column width was initially $25 \mathrm{~nm}$ and the microstructureevolvedto roughly equiaxed grains of $50 \mathrm{~nm}$ average diameter after heat treatment, while forSample Bthe average columnwidthwas $41 \mathrm{~nm}$ and the sample ended withan average grain diameter of $52 \mathrm{~nm}$. Overall, HT-Sample A and HT-Sample B showed similar average grain sizes and grain size distributions.

Based on the observation that the average grain diameter was only $\sim 50 \mathrm{~nm}$ after 96 hours at 800 ${ }^{\circ} \mathrm{C}$, it appears that grain growth is inhibited in the multilayered samples. Since the initial structure has long columnar grains and the final structure has only fine equiaxed grains, the structural evolution is characterized by dramatic changes in grain shape, and the before and after grain sizes cannot be directly compared. However, average grain volumes were estimated by assuming an initial columnar grain length of $500 \mathrm{~nm}$ (which is reasonable based on DF-TEM images such as Fig. $1 \mathrm{~b}$ and $1 \mathrm{~d}$ ). This yields initialaverage grain volumes of $3 \times 10^{5}$ and $7 \times 10^{5} \mathrm{~nm}^{3}$ for Sample A and B, respectively. Byassuming spherical grains in the heat-treated samples, the average grain volumes are approximately $7 \times 10^{4} \mathrm{~nm}^{3}$ for both HT-Sample A and B.Note that these grain sizes are volumetrically smaller by an order of magnitude after heat treatment; not only does the thermal exposure not seem to cause grain growth by, e.g., lateral growth of the columnar grains, it is associated with substantial structural refinement to an equiaxed structure. For the monolithic Sample C, the grains changed from an average column width of $57 \mathrm{~nm}$ to an average grain diameter of $196 \mathrm{~nm}$ (Fig. 3c). For a $500 \mathrm{~nm}$ long columnar grain, this translates to an increase in grain volume from $1 \times 10^{6} \mathrm{~nm}^{3}$ to $4 \times 10^{6} \mathrm{~nm}^{3}$ after heat treatment.

The exact mechanisms responsible for the structural evolution are unknown at this point.Although we envision some process of recrystallization as being involved, the focus here is on the energetics of the annealed structures only.It should be noted that oxygen could also play an important role and thatoxidation will contribute to a more thermally stable structure, as shown in the case of nanocrystalline $\mathrm{Al}$ with differing degrees of oxygen content [6]. In order to determine the oxygen content in the samples, the ring intensities from the TEM diffraction images wereintegrated; after comparing the acquired electron diffraction patterns to the diffraction pattern of $\mathrm{HfO}_{2}$, a significant amount of oxidation was found. Quantifying the amount of $\mathrm{HfO}_{2}$ is difficult due to the mixture of $\mathrm{HfO}_{2}$ peaks with those from $\mathrm{Hf}$ and Ti. Qualitatively we estimate a concentration of several tenths of percent (which is supported by EDS analysis) when compared to the rest of the sample. According to EDS analysis, oxygen values were detected between 5 to 30 at.\% depending on the sample area.However, oxygen does not seem to be solely responsible for the grain evolution or the grain stability in the multilayered samplessince both the 
multilayered and monolithic samples experienced the samelevel of oxidation during the heat treatments. Both types of samples showed a final equiaxed nanocrystalline structure,but whilethe monolithic sample showed apparent grain growth the multilayered structured did not. In the following sections additional parameters will be discussed in more detail.

\subsection{Kinetics}

An estimation of the achievable diffusional distances during heat treatmentofSamples $\mathrm{A}$ and Bwas performed by assuming a 3-D polycrystalline grain geometry. Although the samples started with columnar structures, they ended with mostly equiaxed grains, so this assumption should be sufficient for order-of-magnitude calculations. Since nanocrystalline materials have a substantial volume of grain boundaries and triple junctions, in order to determine the overall sample diffusivity, the diffusion through these areas must be taken into account. For this purpose, the following equation was used to estimatethe self-diffusivity of $\mathrm{Hf}$ (the majority element)[26, 27]:

$$
D_{\text {eff }}=D_{\mathrm{b}}+g(d)\left[\frac{2 H_{\mathrm{gb}} \delta}{d}\left(D_{\mathrm{gb}}-D_{\mathrm{b}}\right)+\frac{H_{\mathrm{tj}} \delta^{2}}{d^{2}}\left(D_{\mathrm{tj}}-D_{\mathrm{b}}\right)\right]
$$

where $D_{\text {eff }}$ is the effective diffusivityin the polycrystalline structure, $D_{\mathrm{b}}$ is the bulk diffusivity within the crystal grains, $D_{\mathrm{gb}}$ is the grain boundary diffusivity, $D_{\mathrm{tj}}$ is the triple junction diffusivity, $\delta$ is the grain boundary thickness (taken to be $0.5 \mathrm{~nm}$ ), and $g(d)$ is a geometrical parameter which can be determined by the following equation:

$$
g(d)=\frac{2 H_{\mathrm{gb}} d^{3}+2 H_{\mathrm{tj}} \delta d^{2}}{\left.6 H_{\mathrm{gb}} d^{3}-\left(2 H_{\mathrm{gb}}^{2}-3 H_{\mathrm{tj}}\right) \delta d^{2}-3 H_{\mathrm{gb}} H_{\mathrm{tj}} \delta^{2} d-H_{\mathrm{tj}}^{2} \delta^{3}\right)}
$$

where $d$ is the grain size and $H_{\mathrm{gb}}=2.9105$ and $H_{\mathrm{tj}}=2.5259$ are structure constants characteristic of alog-normal Voronoi polyhedral structure, corresponding to the grain boundaries and triple junctions, respectively[26].

By assuming ideal solution behavior, this Hf self-diffusivity can be combined with the Ti selfdiffusivity, using Darken's equation [28, 29]:

$$
D_{\text {int }}=X_{\mathrm{Hf}} D_{\mathrm{Ti}}+X_{\mathrm{Ti}} D_{\mathrm{Hf}}
$$

where $D_{\text {int }}$ is the overall sample interdiffusivity and $X_{\mathrm{Hf}}$ and $X_{\mathrm{Ti}}$ are the mole fractions of Hf and Ti. Table 2 shows the different values that were usedand their sources. The bulk diffusivity values $D_{\mathrm{b}}=D_{0} e^{-\frac{Q}{R T}}$ were calculated at $T=800{ }^{\circ} \mathrm{C}$, where $D_{o}$ is the pre-exponential rate constant, $Q$ is the activation energy, and $R$ is the ideal gas constant[30-33]. The grain boundary diffusivity was calculated based on the grain boundary diffusion parameter in the reference given 
and a grain boundary widthof $0.5 \mathrm{~nm}$, while the triple junction diffusivity was assumed to be approximately 100 times as large as the grain boundary diffusivity, which is on the lower end of what has been observed [26, 34-37].

Table 2: Diffusion coefficients and calculated diffusion distances.

\begin{tabular}{|c|c|c|c|c|c|c|}
\hline Species & Path & $D_{0}\left(\mathrm{~m}^{2} / \mathrm{s}\right)$ & $Q(\mathrm{~kJ} / \mathrm{mol})$ & $D\left(\mathrm{~m}^{2} / \mathrm{s}\right)$ & $L(\mathrm{~nm})$ & Ref. \\
\hline Hf & bulk & $5.40 \times 10^{-6}$ & 323 & $1 \times 10^{-21}$ & 20 & {$[30]$} \\
\hline Hf & grain boundary & & & $3 \times 10^{-14}$ & $1 \times 10^{5}$ & {$[34]$} \\
\hline Hf & triple junction & & & $3 \times 10^{-12}$ & $1 \times 10^{6}$ & {$[26]$} \\
\hline Hf in Ti & bulk & $4.00 \times 10^{-6}$ & 254 & $2 \times 10^{-18}$ & $8 \times 10^{2}$ & {$[31]$} \\
\hline Ti & bulk & $1.35 \times 10^{-3}$ & 303 & $2 \times 10^{-18}$ & $9 \times 10^{2}$ & {$[32]$} \\
\hline Ti in Hf & bulk & $2.70 \times 10^{-5}$ & 322 & $6 \times 10^{-21}$ & 40 & {$[33]$} \\
\hline
\end{tabular}

Using these diffusivityvalues, theoverall sample interdiffusivitywas plotted for a temperature of $800{ }^{\circ} \mathrm{C}$ as a function of the grain size in Fig.5. Also included in the plot are the individual diffusivity contributions from the Hf bulk, Hf grain boundaries, and Hf triple junctions. The diffusivity can be used to approximate the chemical diffusion distance, $L$, according to the following equation

$$
L \approx(D t)^{1 / 2}
$$

where $t$ is the time, taken here as 96 hours to match the experiments. The chemical diffusion distances are shownon the right y-axis of Fig. 5, and they are also given in Table 2. At a grain size of $50 \mathrm{~nm}$ (the approximate post-heat-treatment grain size of Sample A and B), the interdiffusivity is $8 \times 10^{16} \mathrm{~m}^{2} / \mathrm{s}$ and the chemical diffusion distance is $16 \mu \mathrm{m}$. This shows that the diffusion length scales that are achievable after 96 hours at $800{ }^{\circ} \mathrm{C}$ are sufficiently large to allow for significant grain growth and chemical redistribution.

While the bulk diffusion distances of $\mathrm{Hf}$ in $\mathrm{Hf}$ and Ti in $\mathrm{Hf}$ are $20 \mathrm{~nm}$ and $40 \mathrm{~nm}$, respectively, which is much smaller than the chemical diffusion distance, it should be noted that all of the atoms started within $20 \mathrm{~nm}$ of a boundary within the multilayered samples prior to heat treatment. Thus, they had the potential to diffuse to the boundaries and subsequently experience much accelerated diffusion rates. In addition, grain growth will occur at grain boundaries and does not require strong diffusion of the intragranular atoms. The significant restructuring of the samples,especially of the co-sputtered sample which was originally homogeneous,confirms these expectations. The final structure of the multilayer samples is much finer than could have, in principle, been accessed kinetically, should the system have preferred to instead evolve to a coarser configuration. 


\subsection{Ti Segregation}

HT-Sample A and B showed strong segregation of Hf-rich and Ti-rich regions (Fig. 2c and 2f). EDX imaging was performed in a TEM to investigate this phenomenon for both samples, andsince they showed very similar structures after heat treatment, results are presented only for HT-Sample B inFig.6. Whilesome oxygen was detected, and the inset diffraction patterns in Fig. 2 indicate that there is a mix of $\mathrm{Hf}$ and $\mathrm{HfO}_{2}$ in the samples, EDX is not well-suited for quantitative measurement of oxygen, and the results are presented on a metals-only basis. Thebright regions in the ADF-STEM image (Fig.6c) correspond to Hf-rich regions (with $\mathrm{Hf}$ mapping in Fig.6a), while the dark regions correspond to Ti-rich regions (with Ti mapping in Fig.6b). A Hf-Ti composition profileobtained by a line scan is shown in Fig.6d along the direction indicated in Fig.6c by the line A-B. There is large change in the Ti content, with a maximum of $\sim 75$ at.\%in some dark regions and a drop to nearly 0 at.\% in the middle of the bright Hf-rich regions. Additionally, these composition values were obtained by scanning the sample in projection, so the measured degree of separation is likely to be an underestimate.

In considering these large composition variations, it must be kept in mind that though $\mathrm{Ti}$ is the minor alloying element, it is still a significant constituent ( 23 at.\%). While some of the thinnerTi-rich regions appear to be just boundary layers around the Hf-rich grains (suggestive of grain boundary segregation), there are also larger Ti-rich regions which appear to be grains of their own.However, under high-resolution TEM (HRTEM) imaging, none of the large Ti-rich regions showed lattice fringes, though lattice fringes were readily apparent in the Hf-rich grains. This suggests an amorphous Ti-rich structure, which is also indicated by the convergent beam electron diffraction (CBED) pattern shown in Fig. 7a, which is from a typical Ti-rich region and has an indistinct ring. In contrast, the pattern on the right, Fig. 7c, was taken from the crystalline Hf-rich region specified in Fig. 7b.A possible explanation for the formation of amorphous regions is given in Section 3.4.

It is intriguing that these Ti-rich regionsdeveloped in this system. Based on the Hf-Ti phase diagram, at $800{ }^{\circ} \mathrm{C}$ and 23 at.\% Ti, the system is expected to show full miscibility [24]. What is more, the diffusion distances from Fig. 5 and Table 2 show that the elements should have been able to kinetically mix during heat treatment of the multilayers, but they did not. Even more counterintuitive is the result for Sample C, where the elements were already mixed and evolved to an unmixed configuration after annealing.

Since we observed some oxidation of the samples, the hafnia-titania phase diagram was also examined, but itdoes not predict the degree of segregationshown in Fig. 6[38].Strong segregation was reported in previous work with nanostructured hafnia-titania samples [38-44], indicating that the oxidation may influence the $\mathrm{Hf}$ and Ti segregation, butit does not explain the differences in grain evolutionbetween the multilayered and monolithic samples. In order to better understand 
the configurational changes in the multilayered samples, Monte Carlo simulations were conducted for the Hf-Ti system.

\subsection{Modeling}

As a starting point for thermodynamic analysis, the expected bulk equilibrium structure of the Hf-23 at.\% Ti system at $800{ }^{\circ} \mathrm{C}$ was simulated by the Monte Carlo method explained in Section 2.2; a forced single crystal structure (with the same grain number for all lattice sites)was generated by prohibiting grain boundary formation, and the result is a homogeneous solid solution of Hf and Ti atoms, shown in Fig.8a as a single grain number map in solid green with an overlay ofTi atom positions asblack dots. The images in Fig. 8 are 2-D cross sections of full 3-D structures.

In contrast to the above bulk equilibrium structure, when the same alloy was allowed to fully equilibrate without the bulk constraint, and permitting intergranular configurations using the procedure described in Section 2.2, the resulting structure is shown in Fig.8d. Again, the black dots are $\mathrm{Ti}$ atoms and the colored background represents the grain structure. The polycrystalline structure is of lower free energy than the bulk equilibrium one, because it evolves upon full equilibration whenboth bulk and polycrystalline states are allowed. The grain sizes in Fig. 8d vary from approximately 10 to $60 \mathrm{~nm}$ in diameter, which is a good qualitative match for our observed grain sizesof the heat-treated samples, Fig. 4.

The grain boundaries in the polycrystal are decorated preferentially with Ti atoms in Fig. 8d, and the simulation reveals that these Ti-rich intergranular regions havefinite thicknesses. Fig. $8 \mathrm{e}$ is a grain number map (Hf and Ti atoms are not differentiated) of the same structureas Fig. 8d, and Fig. 8f shows a magnified view of the area denoted by the black box in Fig. 8e. This magnified view indicates that the Ti-richintergranular regions resemble a disordered interfacial structure, in which solutes take on their own individual grain number. This is not a physical situation, as a single atom cannot constitute a grain; rather, it implies that the system favors a high fraction of intergranular bonding at equilibrium, where the solute Ti atoms are most energetically accommodated. Such configurations are highly degenerate, and the development of "amorphous-like" films rich in Ti at the boundaries is a probable way for the Monte Carlo algorithm to achieve this bonding preference. In any event, the resulting thickened interfaces or amorphous-type regions that the simulation developed are strikingly similar to the interfacial regions observed in the experimental structure, Fig. 7a.

Multilayered Hf-Ti samples were also explicitly constructed to evaluate their internal energies for comparison with those of both the bulk structure, Fig. 8a, and the fully equilibrated structure, Fig. 8d. An example of such a model having $40 \mathrm{~nm}$ thick Hf-Ti layers is shown in Fig. 8b, where Ti atoms are black and the columnar grain structure is represented by the colored map in 
the background. The Ti interlayers are placed along a close-packed direction of the HCP lattice and the columnar grain boundaries are placed along another. To imitate the internal chemical layers of the experimental structures, pure Ti and Hf-Ti solid solution layers of equivalent thicknesses to those in Table 1 are first outlined. After the pure Ti layers are filled, the remaining $\mathrm{Ti}$ atoms which constitute a 23 at.\% global Ti composition are randomly distributed in the rest of the Hf-Ti solid solution layers. The width of the column is assumed to be similar to the combined Ti/Hf-Ti layer thickness, and the column lengths are assumed to be constant and equal to half of the lattice height. By comparing the multilayered configurations (15 and $40 \mathrm{~nm}$ Hf-Ti layer thicknesses), it is shown that the internal energy (Fig. 8c) increases as the thicknesses of the internal layers decrease. This is a result of the inherent energy penalty from unalloyed interfaces that increases with increasing number of internal layers and columnar grain boundaries.

The structures in Fig. 8 can be further compared on the basis of their internal energy, which is approximately equivalent to the enthalpy. Although the Monte Carlo algorithm produced the structures of Fig. 8a and 8d using a thermal process that accounts for entropy, we do not have a quantitative measure of the configurational entropy of these structures, and thus compare only their internal energies, which are given in Fig. 8c. The structures of lowest internal energy are those of the multilayers, which are phase separated, and thus are in line with the classical ground state at $0 \mathrm{~K}$ for the Hf-Ti system (which has a positive heat of mixing). It is the contribution of entropy that permits the bulk solid solution to become the favored bulk or coarse-grained structure at an elevated temperature such as $800^{\circ} \mathrm{C}$. More interestingly, though, at this high temperature of $800^{\circ} \mathrm{C}$ the bulk solid solution is of higher internal energy than the grain boundary segregated polycrystal; even without the contribution of entropy this system would appear to already favor the presence of segregated grain boundaries.

These results therefore suggest that the equiaxed polycrystalline structure is a favored structure at $800^{\circ} \mathrm{C}$ in a thermodynamic sense, with a strong enthalpic contribution to the stability of that structure. This not only aligns with the alloy configurations observed in the experiments, it helps to explain how several very different initial structures, both mixed and unmixed, evolve to a similar nanostructured state with nominally unexpected titanium partitioning around hafniumrich grains. Although the presence of oxygen in the experiments is a confounding factor not captured in the simulations, the present results suggest that interfacial alloy thermodynamics play a strong role in stabilizing a nanostructure in this alloy.

\section{Conclusions}

Sputtered multilayer and monolithic samples were used to investigate thepredicted hightemperature nanograin stability of the Hf-Ti system. TEM imaging of heat-treated samples 
indicated strong Hf and Ti segregation, which was not expected based on the Hf-Ti phase diagram. There is an indication of Ti-rich regions around Hf-rich grains, with some Ti-rich regions appearing to be amorphous. In addition, although both the multilayered and monolithic samples evolve to an equiaxed polycrystalline structure with Ti segregation at grain boundaries, the multilayered samples exhibited retention of a nanoscale internal structurewhereas the monolithic sample showed apparent grain growth.

Monte Carlo simulations were conducted to better understand this phenomenon.It was found that nanograined configurations were obtained from a full thermodynamic equilibration and have lower internal energies than the solid solution Hf-Ti phase that is expected from the phase diagram, which helps explain the observed nanograin stability. The presence of solute-segregated andthickened intergranular regions with disordered structures is also in line with the Ti-rich amorphous regions observed experimentally.

The main advantagesof the multilayer sputtering technique for the study of nanograin stability are control of grain size, global composition, and elemental distribution. This control allows not only for tailored starting configurations that may be close to an energetically favorable state, but also an easier kinetic access to it, as was observed for the multilayered samples in this study. Thus, sputtered multilayers are useful for continuing investigations of nanograin stability and could be a route to produce stable nanograin structures.

\section{Acknowledgements}

This work was performed under the auspices of the Office of Naval Research under Grant N00014-12-1-0638. We acknowledge the Center for Electron Microscopy and Microanalysis at USC for the use of their FIB and TEM instruments.TC acknowledges the computing resources from the National e-Science Infrastructure Consortium of Thailand, and CAS and TC acknowledge the support of the US Army Research Office at MIT, under grantW911NF-14-10539 .

\section{References}

[1] H. Gleiter. NANOCRYSTALLINE MATERIALS, Progress in Materials Science 33 (1989) 223-315.

[2] H. Gleiter. Nanostructured materials: Basic concepts and microstructure, Acta Materialia 48

(2000) 1-29.

[3] T. Suzuoka. Exact Solutions of Two Ideal Cases in Grain Boundary Diffusion Problem and the Application to Sectioning Method, Journal of the Physical Society of Japan 19 (1964) 839-851. 
[4] J.S. Lee, C. Minkwitz, C. Herzig. Grain boundary self-diffusion in polycrystalline tungsten at low temperatures, Phys. Status Solidi B-Basic Res. 202 (1997) 931-940.

[5] B. Gunther, A. Kumpmann, H.D. Kunze. SECONDARY RECRYSTALLIZATION EFFECTS IN NANOSTRUCTURED ELEMENTAL METALS, Scr. Metall. Materialia 27 (1992) 833-838.

[6] J.A. Haber, W.E. Buhro. Kinetic instability of nanocrystalline aluminum prepared by chemical synthesis; Facile room-temperature grain growth, Journal of the American Chemical Society 120 (1998) 10847-10855.

[7] J.W. Cahn. IMPURITY-DRAG EFFECT IN GRAIN BOUNDARY MOTION, Acta Metallurgica 10 (1962) 789-\&.

[8] K. Boylan, D. Ostrander, U. Erb, G. Palumbo, K.T. Aust. AN INSITU TEM STUDY OF THE THERMALSTABILITY OF NANOCRYSTALLINE NI-P, Scr. Metall. Materialia 25 (1991) 2711-2716.

[9] C.C. Koch, R.O. Scattergood, M. Saber, H. Kotan. High temperature stabilization of nanocrystalline grain size: Thermodynamic versus kinetic strategies, Journal of Materials Research 28 (2013) 1785-1791.

[10] Z. Chen, F. Liu, X.Q. Yang, C.J. Shen, Y.M. Zhao. A thermokinetic description of nano-scale grain growth under dynamic grain boundary segregation condition, J. Alloy. Compd. 608 (2014) 338-342.

[11] E. Nes, N. Ryum, O. Hunderi. ON THE ZENER DRAG, Acta Metallurgica 33 (1985) 11-22.

[12] H. Sun, C. Deng. Direct quantification of solute effects on grain boundary motion by atomistic simulations, Comput. Mater. Sci. 93 (2014) 137-143.

[13] J. Weissmüller. Alloy effects in nanostructures, Nanostructured Materials 3 (1993) 261-272.

[14] R. Kirchheim. Grain coarsening inhibited by solute segregation, Acta Materialia 50 (2002) 413-

419.

[15] P.C. Millett, R.P. Selvam, A. Saxena. Stabilizing nanocrystalline materials with dopants, Acta Materialia 55 (2007) 2329-2336.

[16] H.A. Murdoch, C.A. Schuh. Stability of binary nanocrystalline alloys against grain growth and phase separation, Acta Materialia 61 (2013) 2121-2132.

[17] H.A. Murdoch, C.A. Schuh. Estimation of grain boundary segregation enthalpy and its role in stable nanocrystalline alloy design, Journal of Materials Research 28 (2013) 2154-2163.

[18] T. Chookajorn, H.A. Murdoch, C.A. Schuh. Design of Stable Nanocrystalline Alloys, Science 337 (2012) 951-954.

[19] H.J. Fecht, E. Hellstern, Z. Fu, W.L. Johnson. NANOCRYSTALLINE METALS PREPARED BY HIGHENERGY BALL MILLING, Metallurgical Transactions a-Physical Metallurgy and Materials Science 21 (1990) 2333-2337.

[20] A. Revesz, T. Ungar, A. Borbely, J. Lendvai. Dislocations and grain size in ball-milled iron powder, Nanostruct. Mater. 7 (1996) 779-788.

[21] P.P. Choi, J.S. Kim, H.S. Choi, D.H. Kwon, Y.S. Kwon. Production of Cu-Hf-Ti bulk glassy composites by mechanical alloying and spark-plasma sintering. in: Sung JH, Lee CG, You YZ, Lee YK, Kim JY, (Eds.). Heat Treatment of Materials, vol. 118. Trans Tech Publications Ltd, Stafa-Zurich, 2006. pp. 655659.

[22] V. Ronto, F. Tranta, J. Solyom, A. Kovacs, P. Pekker, lop. Investigation of Solidification Behaviour in Cu-based Cu-Hf-Ti alloy system, 3rd International Conference on Advances in Solidification Processes 27 (2012).

[23] X.L. Meng, W. Cai, K.T. Lau, L.M. Zhou, L.C. Zhao. Phase transformation and thermal stability of aged Ti-Ni-Hf high temperature shape memory alloys, J. Mater. Sci. Technol. 22 (2006) 691-695.

[24] H. Okamoto. Hf-Ti (hafnium-titanium), J. Phase Equilib. 18 (1997) 672-672. 
[25] T. Chookajorn, C.A. Schuh. Thermodynamics of stable nanocrystalline alloys: A Monte Carlo analysis, Physical Review B 89 (2014).

[26] Y. Chen, C.A. Schuh. Geometric considerations for diffusion in polycrystalline solids, J. Appl. Phys. 101 (2007).

[27] T. Chookajorn, C.A. Schuh. Nanoscale segregation behavior and high-temperature stability of nanocrystalline W-20 at.\% Ti, Acta Materialia 73 (2014) 128-138.

[28] R.E. Rudd, W.H. Cabot, K.J. Caspersen, J.A. Greenough, D.F. Richards, F.H. Streitz, P.L. Miller. Self-diffusivity and interdiffusivity of molten aluminum-copper alloys under pressure, derived from molecular dynamics, Phys. Rev. E 85 (2012).

[29] L.S. Darken. DIFFUSION, MOBILITY AND THEIR INTERRELATION THROUGH FREE ENERGY IN BINARY METALLIC SYSTEMS, Transactions of the American Institute of Mining and Metallurgical Engineers 175 (1948) 184-201.

[30] C. Herzig, Y. Mishin, S. Divinski. Bulk and interface boundary diffusion in group IV hexagonal close-packed metals and alloys, Metall. Mater. Trans. A-Phys. Metall. Mater. Sci. 33 (2002) 765-775.

[31] R.A. Pérez, F. Dyment, G.G. Bermúdez, H. Somacal, D. Abriola. Measurements of Hf diffusion in $\alpha$-Ti by HIRBS, Journal of Nuclear Materials 207 (1993) 221-227.

[32] M. Köppers, C. Herzig, M. Friesel, Y. Mishin. Intrinsic self-diffusion and substitutional Al diffusion in $\alpha$-Ti, Acta Materialia 45 (1997) 4181-4191.

[33] M. Köppers, C. Herzig, U. Södervall, A. Lodding. Volume Diffusion of Titanium in $\alpha$-Hafnium Single Crystals - A Combined Study of SIMS and Tracer Experiments. Defect and Diffusion Forum, vol. 95: Trans Tech Publications, 1993. p.783-792.

[34] F. Guthoff, Y. Mishin, C. Herzig. SELF-DIFFUSION ALONG STATIONARY AND MOVING GRAINBOUNDARIES IN ALPHA-HF, Z. Metallk. 84 (1993) 584-591.

[35] B. Bokstein, V. Ivanov, O. Oreshina, A. Peteline, S. Peteline. Direct experimental observation of accelerated Zn diffusion along triple junctions in Al, Mater. Sci. Eng. A-Struct. Mater. Prop. Microstruct. Process. 302 (2001) 151-153.

[36] L.M. Klinger, L.A. Levin, A.L. Petelin. The model of triple junction diffusion, Defect and Diffusion Forum 143 (1997) 1523-1526.

[37] A. Peteline, S. Peteline, O. Oreshina. Triple junction diffusion: Experiments and models, Scitec Publications Ltd, Uetikon-Zuerich, 2001.

[38] J.P. Coutures, J. Coutures. THE SYSTEM HFO2-TIO2, J. Am. Ceram. Soc. 70 (1987) 383-387.

[39] M. Popovici, A. Delabie, S. Van Elshocht, S. Clima, G. Pourtois, L. Nyns, K. Tomida, N. Menou, K. Opsomer, J. Swerts, C. Detavernier, D. Wouters, J.A. Kittl. Growth and Material Characterization of Hafnium Titanates Deposited by Atomic Layer Deposition, J. Electrochem. Soc. 156 (2009) G145-G151.

[40] R. Ruh, G.W. Hollenberg, E.G. Charles, V.A. Patel. Phase Relations and Thermal Expansion in the System HfO2-TiO2, J. Am. Ceram. Soc. 59 (1976) 495-499.

[41] D.H. Triyoso, R.I. Hegde, S. Zollner, M.E. Ramon, S. Kalpat, R. Gregory, X.D. Wang, J. Jiang, M. Raymond, R. Rai, D. Werho, D. Roan, B.E. White, P.J. Tobin. Impact of titanium addition on film characteristics of $\mathrm{HfO} 2$ gate dielectrics deposited by atomic layer deposition, J. Appl. Phys. 98 (2005).

[42] M.C. Cisneros-Morales, C.R. Aita. Crystallization, metastable phases, and demixing in a hafniatitania nanolaminate annealed at high temperature, J. Vac. Sci. Technol. A 28 (2010) 1161-1168.

[43] M.C. Cisneros-Morales, C.R. Aita. Intrinsic metastability of orthorhombic HfTiO4 in thin film hafnia-titania, Applied Physics Letters 98 (2011).

[44] M.C. Cisneros-Morales, C.R. Aita. Mixed cation phases in sputter deposited HfO(2)-TiO(2) nanolaminates, Applied Physics Letters 93 (2008). 


\section{Figure Captions}

Fig. 1.Cross-sectional TEM images of as-sputtered nanometallic multilayered composite samples. Sample A consists of $15 \mathrm{~nm} \mathrm{Hf-Ti/2} \mathrm{nm} \mathrm{Ti} \mathrm{layers,} \mathrm{see} \mathrm{(a)} \mathrm{and} \mathrm{(b),} \mathrm{and} \mathrm{Sample} \mathrm{B}$ consists of $40 \mathrm{~nm} \mathrm{Hf-Ti/5} \mathrm{nm} \mathrm{Ti} \mathrm{layers,} \mathrm{see} \mathrm{(c)} \mathrm{and} \mathrm{(d).} \mathrm{In} \mathrm{the} \mathrm{bright-field} \mathrm{TEM} \mathrm{images,} \mathrm{(a)} \mathrm{and}$ (c), the Ti layers are bright and the Hf-Ti layers are dark. The dark-field TEM images, (b) and (d), demonstrate the columnar structures of the samples, with their respective SAED patterns. The growth direction is indicated on the left, and the widths of several columnar grains are marked with arrows in (d). (color online)

Fig. 2. Cross-sectional TEM images of heat-treated $\left(800^{\circ} \mathrm{C}, 96\right.$ hours $)$ nano metallic multilayer composite samples. The first sample is HT-Sample A, which originally consisted of $15 \mathrm{~nm}$ Hf$\mathrm{Ti} / 2 \mathrm{~nm}$ Ti layers, see (a), (b), and (c). The second sample, HT-Sample B, originally consisted of $40 \mathrm{~nm} \mathrm{Hf}-\mathrm{Ti} / 5 \mathrm{~nm}$ Ti layers, see (d), (e), and (f). The bright-field TEM images in (a) and (d) show the nanocrystallinity of the samples, with inset SAED patterns and superimposed reference diffraction patterns of $\mathrm{Hf}$ (bottom right, innermost ring is (100)) and $\mathrm{HfO}_{2}$ (top right, innermost ring is (100)), and the growth direction is indicated on the left. Dark-field TEM images, (b) and (e), show individual grains. The annular dark-field STEM images, (c) and (f), display the Hf and Ti segregation, with Hf-rich regions appearing bright and Ti-rich regions appearing dark.

Fig. 3. Cross-sectional dark-field TEM image (a) of as-sputtered Sample C (co-sputtered Hf-Ti sample, 20 at.\% Ti). The growth direction is indicated on the left. Annular dark-field STEM (b) and dark-field TEM (d) images are shown of the heat-treated sample ( $800^{\circ} \mathrm{C}, 96$ hours), HTSample C. Dark areas are Hf-rich and bright areas are Ti-rich in (b). The grain column widths before heat treatment and grain diameters after heat treatment are given in (c), with an average grain column width of $57 \mathrm{~nm}$ before heat treatment and an average grain diameterof $196 \mathrm{~nm}$ after heat treatment. (color online)

Fig. 4. Grain size distributions for as-sputtered $(\mathrm{a}, \mathrm{c})$ and heat-treated $\left(800^{\circ} \mathrm{C}, 96\right.$ hours $)(\mathrm{b}, \mathrm{d})$ nanometallic multilayered composite samples, Sample A (15 nm Hf-Ti/2 nm Ti) and Sample B (40 nm Hf-Ti/5 nm Ti). The average grain column widthsbefore heat treatment are as follow: (a) Sample A: $25 \mathrm{~nm}$ and (c) Sample B: $41 \mathrm{~nm}$. The average grain diameters after heat treatment are as follow: (b)HT-Sample A: $50 \mathrm{~nm}$ and (d) HT-Sample B: $52 \mathrm{~nm}$. (color online)

Fig. 5. Calculated Hf diffusivities and 96-hour diffusion distances at $800^{\circ} \mathrm{C}$ for triple junctions, grain boundaries, and bulk Hf diffusion, as well as overall Hf-Ti interdiffusion, as a function of grain size.

Fig. 6. Cross-sectional Hf (a) and Ti (b) compositional maps recorded by EDX in a TEM for HTSample B. The sample originally consisted of alternating $40 \mathrm{~nm} \mathrm{Hf}-\mathrm{Ti} / 5 \mathrm{~nm}$ Ti layers and was 
heat treated at $800{ }^{\circ} \mathrm{C}$ for 96 hours. An annular dark-field STEM image is shown from the same area in (c). A linescan compositional profile (d) is shown for $\mathrm{Hf}$ and $\mathrm{Ti}$, along the A-B line located in (c). (color online)

Fig. 7. Convergent beam electron diffraction (CBED) patterns from a Ti-rich (a) and a Hf-rich (c) region of HT-Sample B (a heat-treated $40 \mathrm{~nm}$ Hf-Ti/5 nm Ti multilayer sample). The locations where these patterns were recorded are pointed out by arrows in the cross-sectional TEM image in (b). The scale bar in (b) is $20 \mathrm{~nm}$ long.

Fig. 8. Monte Carlo models of Hf-Ti structures (23 at.\% Ti) at $800{ }^{\circ} \mathrm{C}$, shown for (a)theforcedbulk structure, (b) the nano metallic multilayered structure with $40 \mathrm{~nm}$ Hf-Ti layer thickness, and (d)the fully equilibrated structure. A grain distribution mapof the structure in (d)is shown in (e) and (f) shows a magnified view of the area denoted by a black box in (e). A table of the calculated internal energies for different configurations is shown in (c). (color online) 

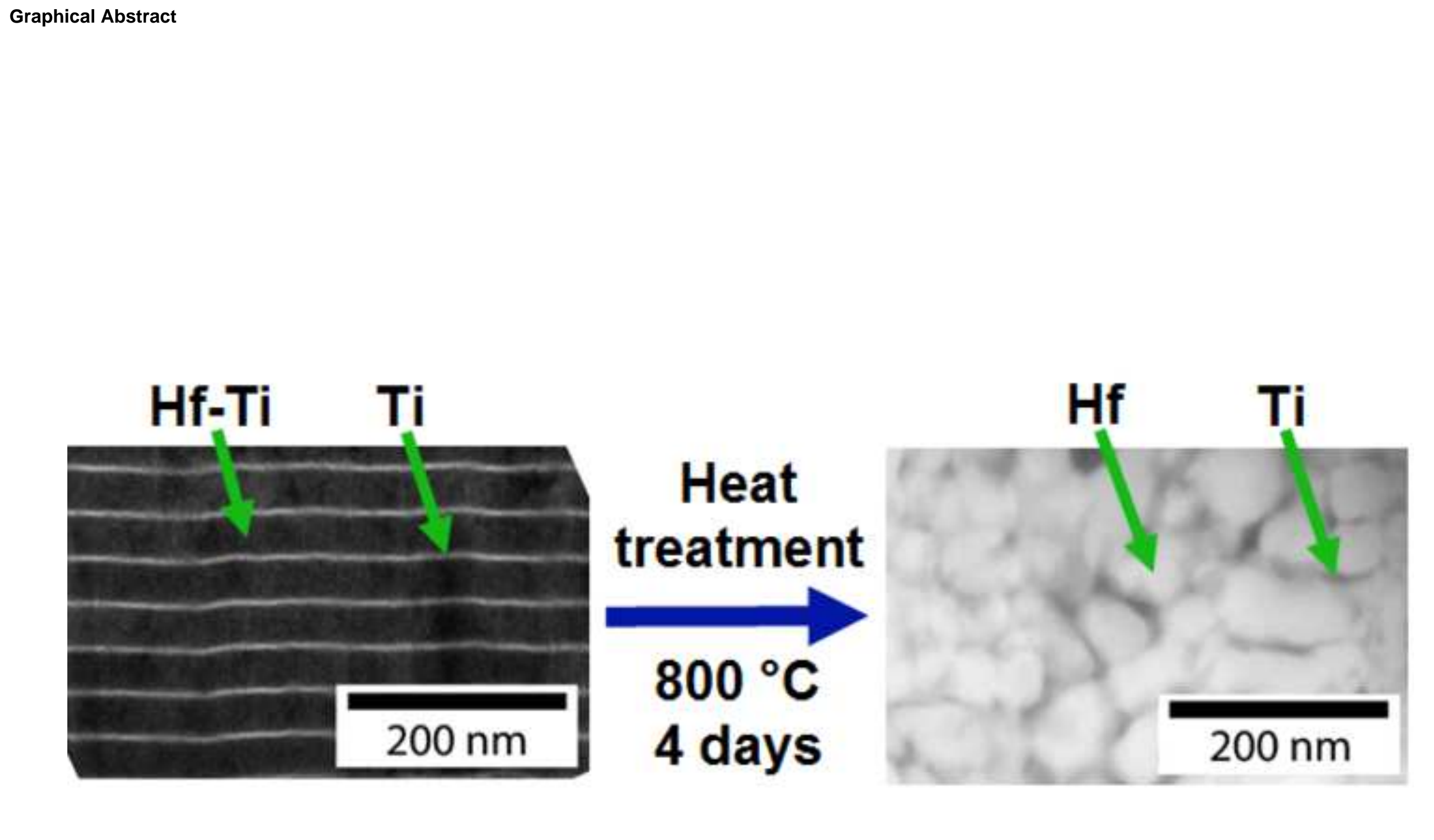

\section{treatment $800^{\circ} \mathrm{C}$ 4 days}

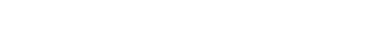

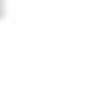




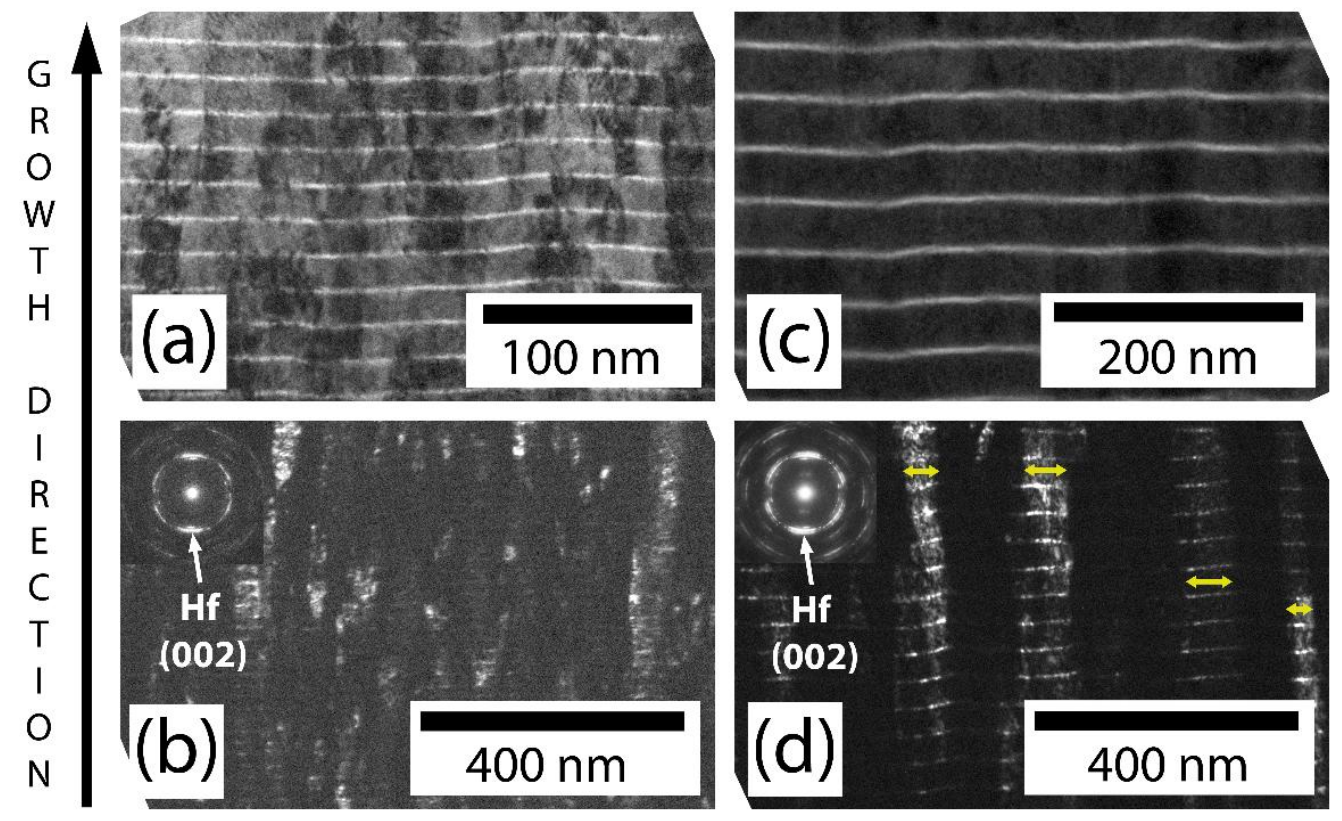

Fig. 1. Cross-sectional TEM images of as-sputtered nano metallic multilayered composite samples. Sample A consists of $15 \mathrm{~nm} \mathrm{Hf}-\mathrm{Ti} / 2 \mathrm{~nm}$ Ti layers, see (a) and (b), and Sample B consists of $40 \mathrm{~nm} \mathrm{Hf}-\mathrm{Ti} / 5$ $\mathrm{nm}$ Ti layers, see (c) and (d). In the bright-field TEM images, (a) and (c), the Ti layers are bright and the $\mathrm{Hf}$-Ti layers are dark. The dark-field TEM images, (b) and (d), demonstrate the columnar structures of the samples, with their respective SAED patterns. The growth direction is indicated on the left, and the widths of several columnar grains are marked with arrows in (d). (color online) 

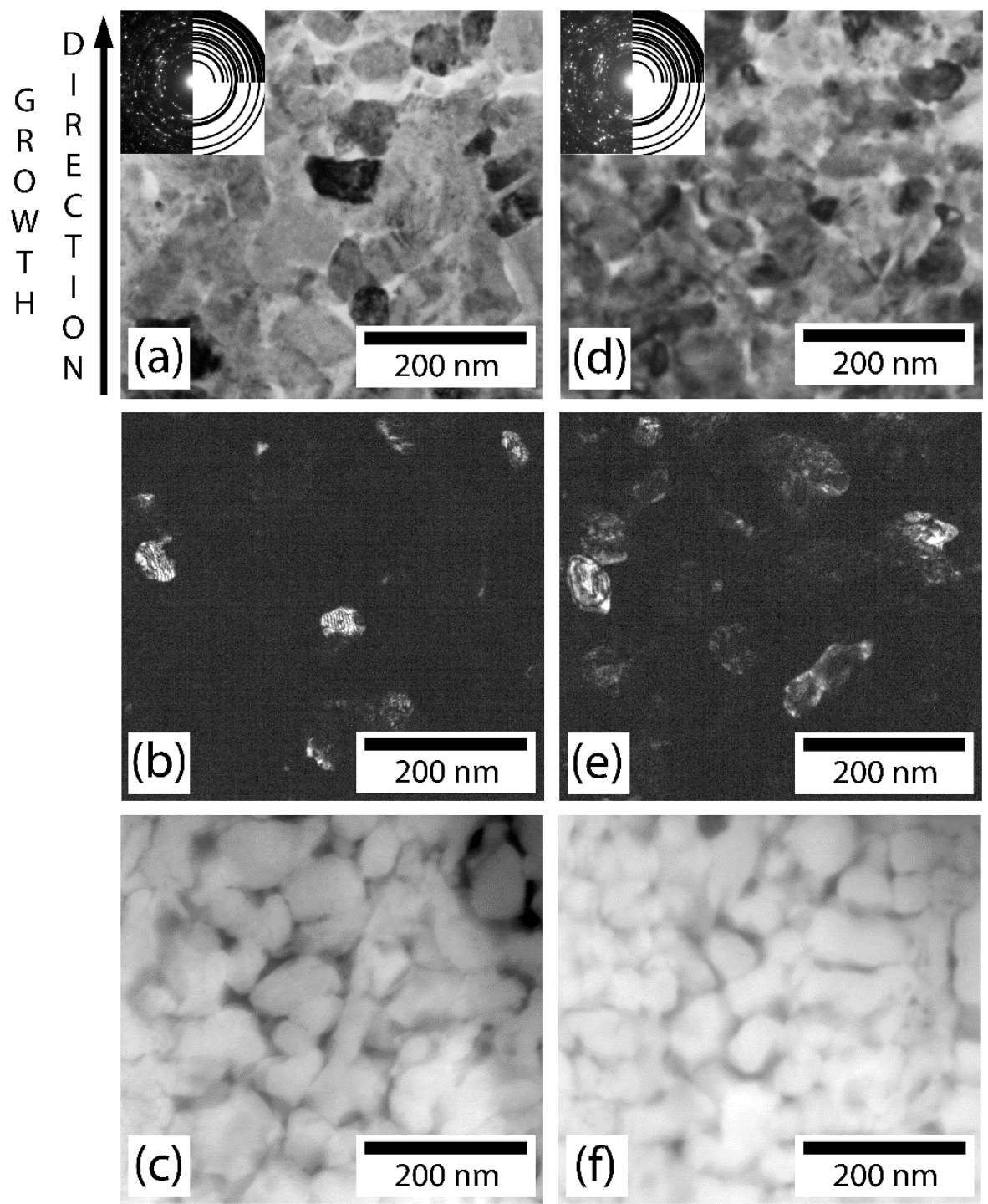

Fig. 2. Cross-sectional TEM images of heat-treated ( $800^{\circ} \mathrm{C}, 96$ hours) nano metallic multilayer composite samples. The first sample is HT-Sample A, which originally consisted of $15 \mathrm{~nm} \mathrm{Hf}-\mathrm{Ti} / 2 \mathrm{~nm}$ Ti layers, see (a), (b), and (c). The second sample, HT-Sample B, originally consisted of $40 \mathrm{~nm} \mathrm{Hf-Ti/5} \mathrm{nm} \mathrm{Ti} \mathrm{layers,} \mathrm{see}$ (d), (e), and (f). The bright-field TEM images in (a) and (d) show the nanocrystallinity of the samples, with inset SAED patterns and superimposed reference diffraction patterns of $\mathrm{Hf}$ (bottom right, innermost ring is (100)) and $\mathrm{HfO}_{2}$ (top right, innermost ring is (100)), and the growth direction is indicated on the left. Dark-field TEM images, (b) and (e), show individual grains. The annular dark-field STEM images, (c) and (f), display the $\mathrm{Hf}$ and Ti segregation, with $\mathrm{Hf}$-rich regions appearing bright and Tirich regions appearing dark. 

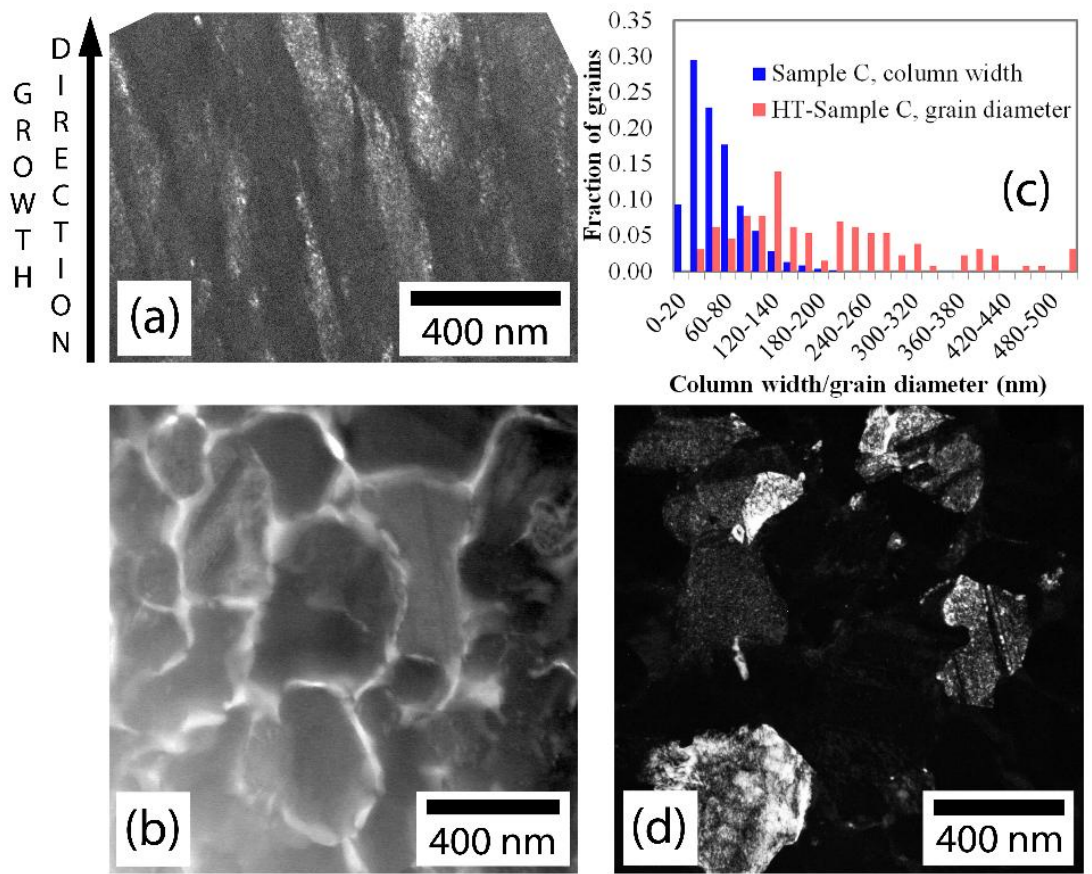

Fig. 3. Cross-sectional dark-field TEM image (a) of as-sputtered Sample C (co-sputtered Hf-Ti sample, 20 at.\% Ti). The growth direction is indicated on the left. Annular dark-field STEM (b) and dark-field TEM (d) images are shown of the heat-treated sample $\left(800^{\circ} \mathrm{C}, 96\right.$ hours), HT-Sample C. Dark areas are Hfrich and bright areas are Ti-rich in (b). The grain column widths before heat treatment and grain diameters after heat treatment are given in (c), with an average grain column width of $57 \mathrm{~nm}$ before heat treatment and an average grain diameter of $196 \mathrm{~nm}$ after heat treatment. (color online) 


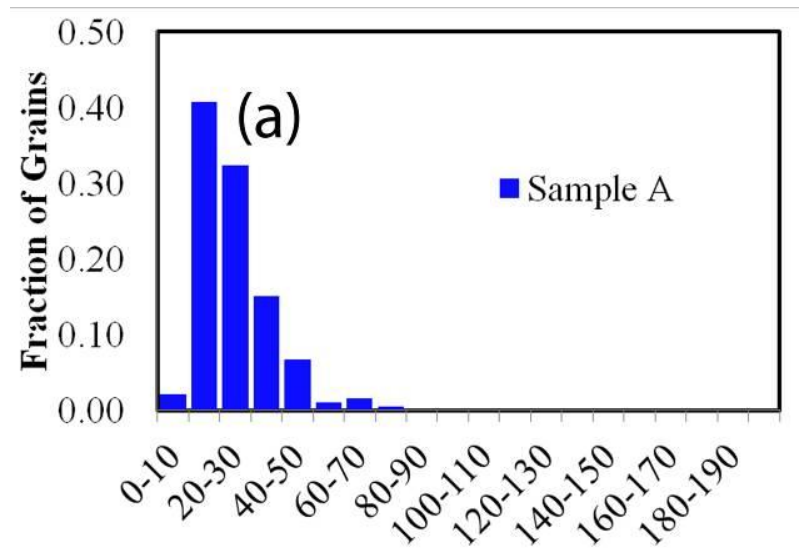

Column width (nm)

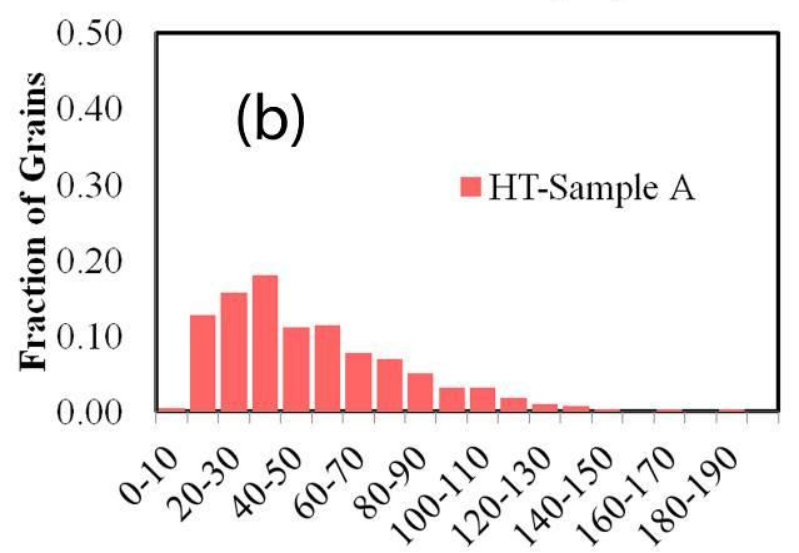

Grain diameter $(\mathbf{n m})$

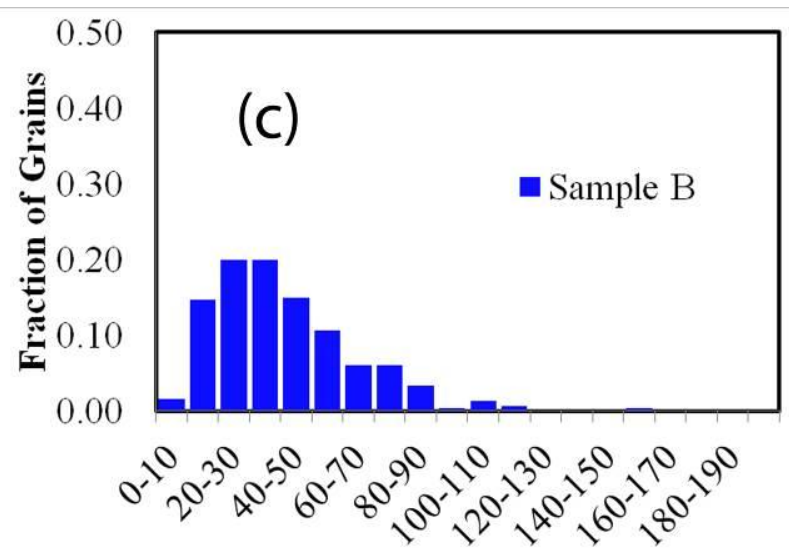

Column width (nm)

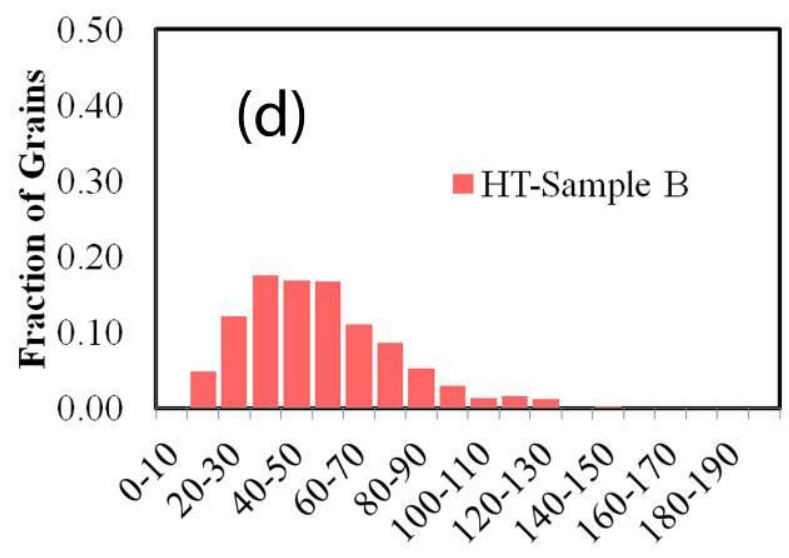

Grain diameter $(\mathbf{n m})$

Fig. 4. Grain size distributions for as-sputtered (a, c) and heat-treated ( $800{ }^{\circ} \mathrm{C}, 96$ hours) $(b$, d) nano metallic multilayered composite samples, Sample A (15 nm Hf-Ti/2 nm Ti) and Sample B (40 nm Hf-Ti/5 $\mathrm{nm} \mathrm{Ti}$ ). The average grain column widths before heat treatment are as follow: (a) Sample A: $25 \mathrm{~nm}$ and (c) Sample B: $41 \mathrm{~nm}$. The average grain diameters after heat treatment are as follow: (b) HT-Sample A: $50 \mathrm{~nm}$ and (d) HT-Sample B: $52 \mathrm{~nm}$. (color online) 


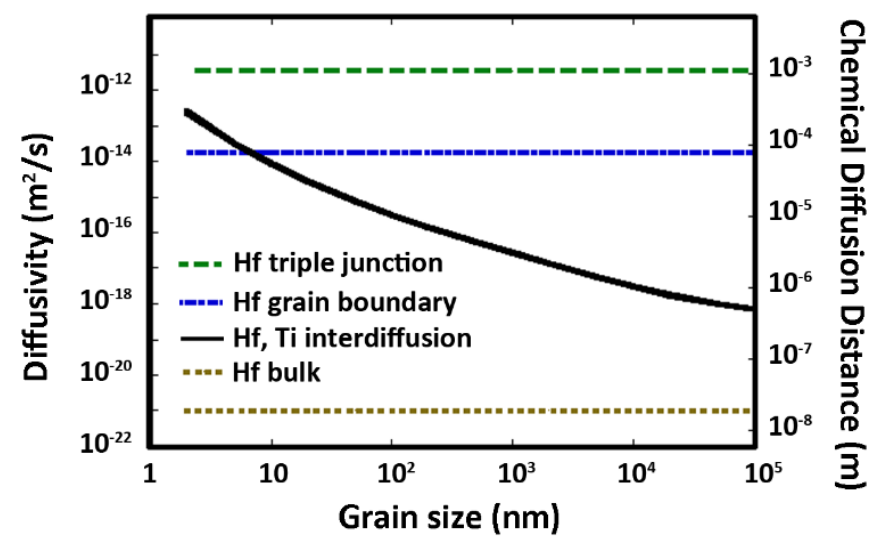

Fig. 5. Calculated $\mathrm{Hf}$ diffusivities and 96 -hour diffusion distances at $800^{\circ} \mathrm{C}$ for triple junctions, grain boundaries, and bulk $\mathrm{Hf}$ diffusion, as well as overall $\mathrm{Hf}-\mathrm{Ti}$ interdiffusion, as a function of grain size.
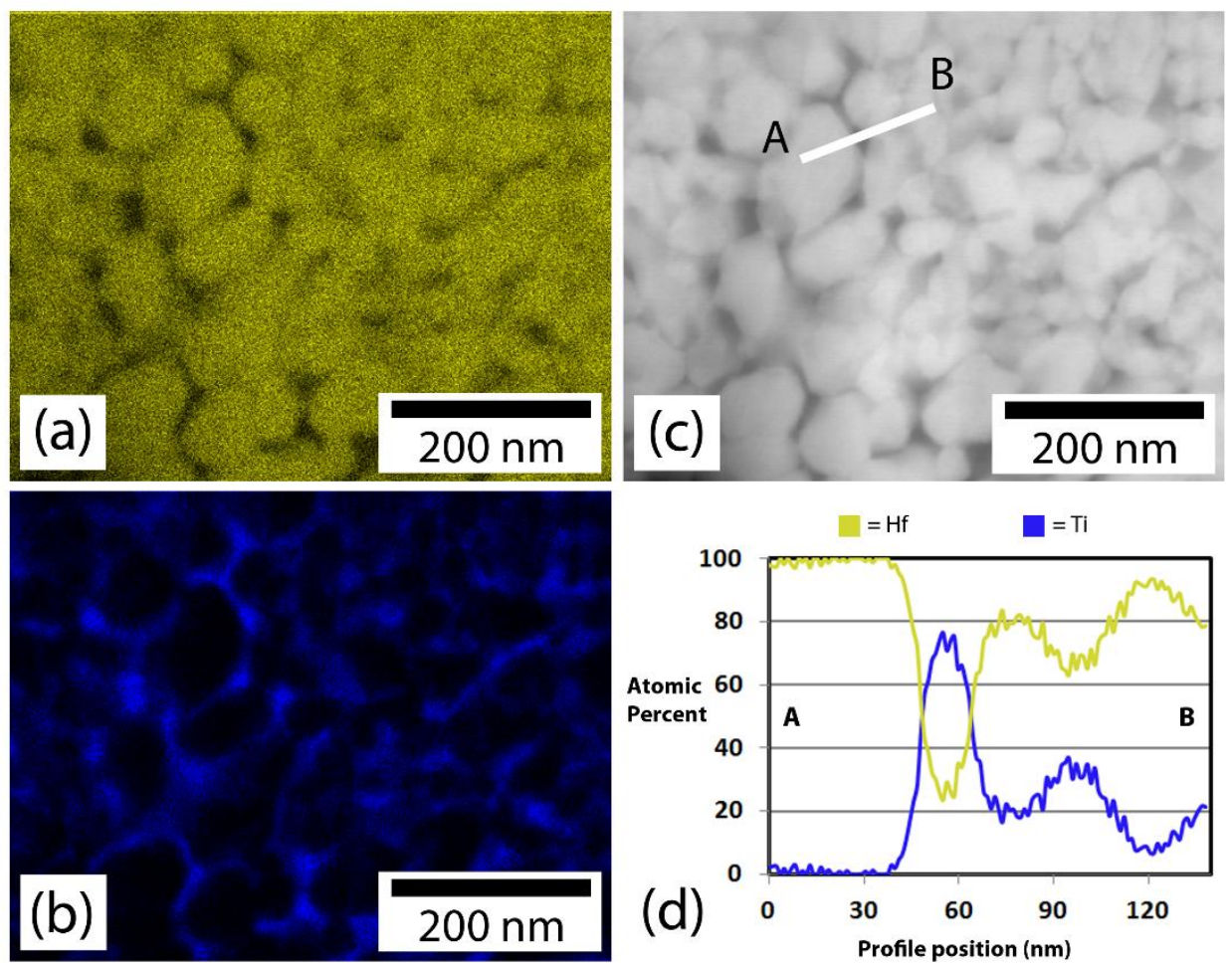

Fig. 6. Cross-sectional $\mathrm{Hf}(\mathrm{a})$ and Ti (b) compositional maps recorded by EDX in a TEM for HT-Sample B. The sample originally consisted of alternating $40 \mathrm{~nm} \mathrm{Hf}-\mathrm{Ti} / 5 \mathrm{~nm}$ Ti layers and was heat treated at $800{ }^{\circ} \mathrm{C}$ for 96 hours. An annular dark-field STEM image is shown from the same area in (c). A linescan compositional profile $(\mathrm{d})$ is shown for $\mathrm{Hf}$ and $\mathrm{Ti}$, along the $\mathrm{A}-\mathrm{B}$ line located in (c). (color online) 

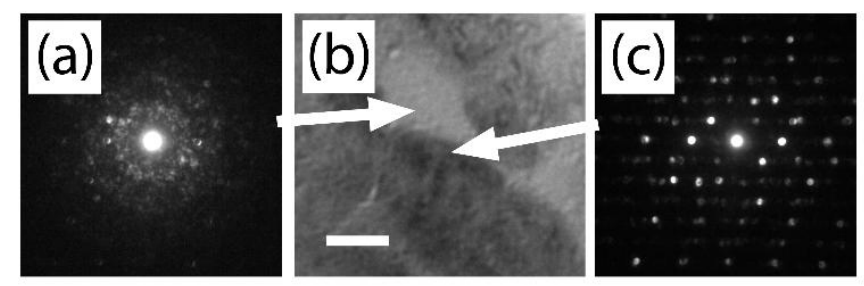

Fig. 7. Convergent beam electron diffraction (CBED) patterns from a Ti-rich (a) and a Hf-rich (c) region of HT-Sample B (a heat-treated $40 \mathrm{~nm} \mathrm{Hf}-\mathrm{Ti} / 5 \mathrm{~nm}$ Ti multilayer sample). The locations where these patterns were recorded are pointed out by arrows in the cross-sectional TEM image in (b). The scale bar in (b) is $20 \mathrm{~nm}$ long.
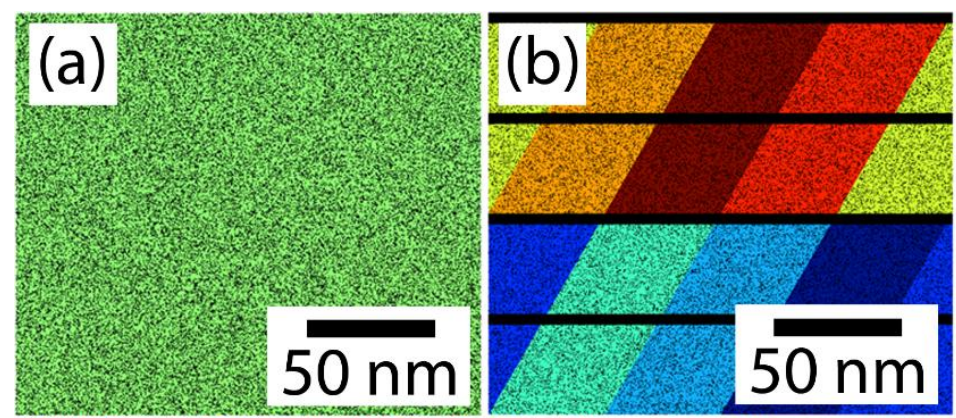

\begin{tabular}{|c|c|}
\hline$(C)$ & \multicolumn{1}{c|}{$\begin{array}{c}\text { Internal } \\
\text { Energy } \\
(\mathbf{k J} / \mathrm{mol})\end{array}$} \\
\hline Structure & \multicolumn{1}{|c|}{$\begin{array}{c}\text { Bulk } \\
-880.73\end{array}$} \\
\hline Equilibrated & -880.90 \\
\hline $15 \mathrm{~nm}$ layers & -881.39 \\
\hline $40 \mathrm{~nm}$ layers & -881.53 \\
\hline
\end{tabular}
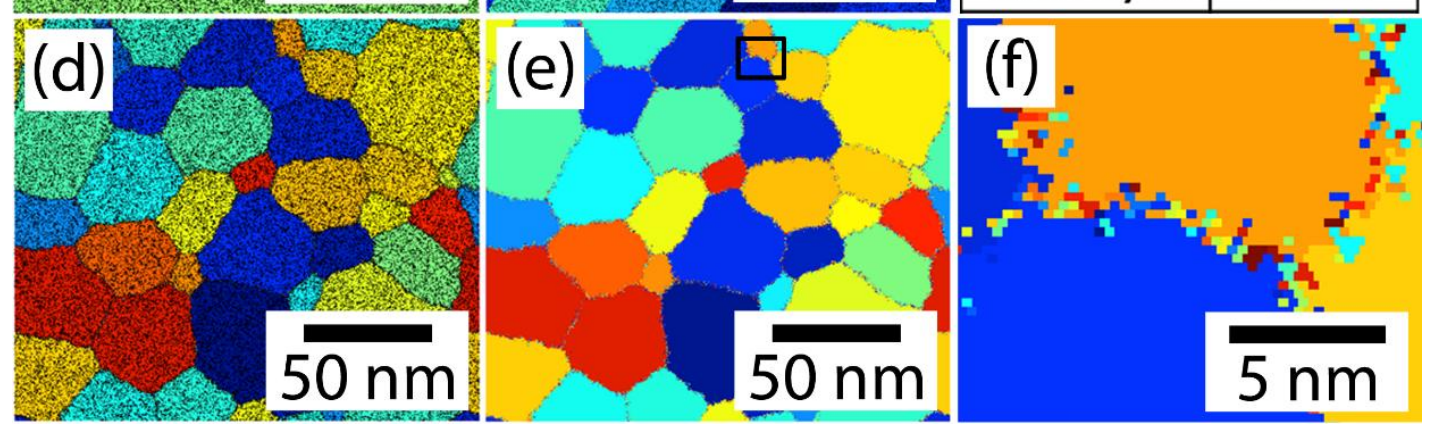

Fig. 8. Monte Carlo models of Hf-Ti structures (23 at.\% Ti) at $800^{\circ} \mathrm{C}$, shown for (a) the forced bulk structure, (b) the nano metallic multilayered structure with $40 \mathrm{~nm} \mathrm{Hf-Ti} \mathrm{layer} \mathrm{thickness,} \mathrm{and} \mathrm{(d)} \mathrm{the} \mathrm{fully}$ equilibrated structure. A grain distribution map of the structure in (d) is shown in (e) and (f) shows a magnified view of the area denoted by a black box in (e). A table of the calculated internal energies for different configurations is shown in (c). (color online) 